\title{
Límite prosódico y sintagmático: estudio comparativo entre zonas de Colombia e Islas Canarias (España)
}

\author{
Prosodic and syntagmatic limits: comparative study among various areas in \\ Colombia and in the Canary Islands (Spain)
}

\author{
Mercedes Amparo Muñetón Ayala y Josefa Dorta Luis ${ }^{2}$ \\ ${ }^{1}$ Universidad de Antioquia. Correo electrónico: mercedes.muneton@udea.edu.co \\ ${ }^{2}$ Universidad de La Laguna. Correo electrónico: jdorta@ull.edu.es
}

\begin{abstract}
Este trabajo se ha realizado en el marco del proyecto internacional AMPER y, más específicamente, en el de AMPER-Col y AMPER-Can. El objetivo es analizar la validez de la hipótesis demarcativa de la frecuencia fundamental (F0) en oraciones declarativas e interrogativas de voces femeninas y masculinas. Para ello, analizamos la sincronización pico/ acento/frontera sintagmática en el pretonema y en el tonema de oraciones $\mathrm{SVO}, \mathrm{S}+\mathrm{EXP}+\mathrm{V}+\mathrm{O}$ y $\mathrm{S}+\mathrm{V}+\mathrm{O}+\mathrm{EXP}$ cuyos núcleos y expansiones (salvo en el $\mathrm{SV}$ ) están conformados por palabras trisílabas de diferente tipología acentual (oxítona, paroxítona y proparoxítona). Los principales resultados muestran una tendencia general a la alineación de los picos máximos con una vocal átona posterior a la tónica y con una frontera sintagmática; por tanto confirman la validez de la hipótesis demarcativa de la entonación en el habla canaria y colombiana.
\end{abstract}

Palabras clave: entonación, acento, límites prosódicos, pretonema, tonema.

This research has been conducted as part of the framework of the international project, AMPER, specifically the AMPER-Col and AMPER-Can. The main objective of this research is to analyze the demarcation hypothesis of fundamental frequency (F0) in the declarative and interrogative sentences of female and male voices. In order to do so, the following was analyzed: the peak/stress/syntagmatic border synchronizations in pretonemes and tonemes in $\mathrm{SVO}, \mathrm{S}+\mathrm{EXP}+\mathrm{V}+\mathrm{O}$ and $\mathrm{S}+\mathrm{V}+\mathrm{O}+\mathrm{EXP}$ sentences whose nucleus and expansions (except $\mathrm{V}$ ) are conformed by trisillable words with different stress categories (oxytones, paroxytones and proparoxytones). Results reveal a tendency of a general alignment between the peaks with post-tonic vowels and with syntagmatic borders, therefore confirming the demarcation hypothesis in Canarian and Colombian speech.

Keywords: intonation, stress, syntagmatic border, pretoneme, toneme. 


\section{INTRODUCCIÓN}

El presente trabajo se realiza en el marco del proyecto internacional AMPER (Atlas Multimedia de Prosodia del Espacio Románico) ${ }^{1}$ y, más específicamente, en el de AMPER-Col (AMPER en Colombia) y AMPER-Can (AMPER en Canarias)2. AMPER inicia su andadura en los albores del siglo XXI, aunque la idea se fue gestando a finales del siglo XX por investigadores del "Centre de Dialectologie" de la Université Stendhal Grenoble 3 en Francia, bajo el impulso del profesor Michel Contini. Su objetivo principal consiste en analizar y comparar la prosodia de las diferentes lenguas y variedades románicas y, además, reflejar los principales resultados en mapas que puedan ser consultados con apoyo visual y auditivo a través de internet. Para ello, se pretende estudiar los tres parámetros acústicos que modifican los patrones entonativos, esto es, la frecuencia fundamental, la duración y la intensidad. Además de los países europeos de habla románica, poco a poco se han incorporado países de América Latina, entre ellos podemos mencionar a Venezuela, Chile y Colombia ${ }^{3}$.

La tradición del estudio prosódico en general y el de la entonación en particular era prácticamente inexistente en Colombia y en Canarias. Desde finales del siglo $\mathrm{XX}$, en correspondencia con la producción de este tipo de estudios en diversas lenguas y variedades, esta temática es foco de interés para los investigadores. Con todo, en Colombia los trabajos entonativos siguen siendo muy escasos ( $v . g r$. Ham 2003; Osorio y Muñoz 2011); en cambio, en Canarias han proliferado los estudios en la última década por lo que se cuenta ya con muchos trabajos sobre la entonación y el acento de las diferentes Islas Canarias (v. gr. Dorta et al. 2013) . Recientemente, gracias a AMPER-Col, se ha iniciado el análisis sistemático de la prosodia en diferentes localidades del país y, como consecuencia, se ha comenzado a publicar algunos resultados parciales (véase Muñetón y Dorta 2015; Muñetón, 2016). Además, siguiendo las directrices marcadas por el proyecto internacional AMPER, estos resultados ya han comenzado a ser comparados con los obtenidos en otras variedades del español, como la venezolana de Mérida (Díaz et al. 2015, en prensa).

Precisamente, en este marco comparativo se encuadra el presente trabajo en el que comparamos dos zonas colombianas (Medellín y Bogotá) con dos canarias (Tenerife y Gran Canaria) con el propósito de comprobar si la estructura prosódica de una oración se relaciona con su estructura sintáctico-semántica de acuerdo con la

\footnotetext{
Los coordinadores generales hasta el mediados de 2015 han sido Michel Contini (Université Stendhal-Grenoble 3) y Antonio Romano (Università di Torino). Este último es el coordinador general en la actualidad.

2 El trabajo se vincula a dos proyectos de investigación: Relaciones entre el límite prosódico y el límite sintagmático en oraciones declarativas e interrogativas de voces femeninas y masculinas de Colombia e Islas Canarias (España), Universidad de Antioquia, Comité para el Desarrollo de la Investigación (CODI), IP Mercedes Muñetón Ayala y Estudio comparativo de la entonación y del acento en zonas fronterizas del español (FFI2014-52716-P), proyecto de I+D del Programa Estatal de Fomento de la Investigación Científica y Técnica de Excelencia, Subprograma Estatal de Generación del Conocimiento del Ministerio de Economía y Competitividad de España, IP Josefa Dorta. Las autoras del trabajo son investigadoras de ambos proyectos.
}

3 Página WEB de AMPER internacional donde se pueden observar ejemplos de la prosodia de diferentes países europeos y latinoamericanos: http://stel.ub.edu/labfon/amper/cast/index_internacional.html.

${ }_{4}$ En http://ampercan.webs.ull.es/ se puede consultar numerosos trabajos relacionados con la entonación canaria. 
hipótesis del modelo fonológico de Philippe Martin (1987, 1997). Al contrario de lo que se postula tradicionalmente en algunos trabajos, esto es, que el acento coincide o se sincroniza con una prominencia tonal (Apud. Llisterri et al. 1995), en otros se ha demostrado que en español no se da tal sincronización, pues la tendencia generalizada es el desplazamiento o posrealización del pico tonal (Garrido et al. 1993; Prieto et al. 1995; Sosa 1995, 1999; Face 2002, entre otros), esto es, el fenómeno de overshooting. Asimismo, se ha sugerido que lo normal es el alineamiento del pico tonal con la postónica y que en menor medida se presenta el preshooting o anticipación del pico.

La posrealización del pico tonal se ha comprobado también en varios trabajos realizados en el marco de AMPER. Así, Pamies y Amorós (2005) analizaron la entonación de un corpus formal, emitido por dos mujeres granadinas urbanas, compuesto de frases declarativas del tipo sujeto + verbo + objeto (SVO), con expansión y sin expansión en el sujeto y con distintas distribuciones acentuales. Los resultados mostraron que en el $100 \%$ de los pretonemas los picos tonales demarcan las fronteras entre palabras y más específicamente entre los sintagmas. Se sugiere así que la entonación puede tener una función demarcativa, como una alternativa a la teoría autosegmental.

Dorta (2006), por su parte, en el marco de AMPER-Can, tiene en cuenta la relación entre picos tonales, acentos y límites morfológicos en un corpus de oraciones interrogativas SVO sin expansión en el sintagma nominal (núcleo trisílabo simple) y con expansión en dicho sintagma (núcleo trisílabo + expansión trisílaba) emitidas por una informante urbana de Tenerife. En dicho corpus se dan todas las combinaciones posibles de los acentos en español (oxítona, paroxítona y proparoxítona). El estudio se centró en el pretonema teniendo en cuenta dos tipos de límites sintagmáticos: uno fuerte situado entre el sintagma nominal y el sintagma verbal y otro débil que separa el núcleo y la expansión del sintagma nominal. Se concluyó que tanto en las interrogativas con SN simple como en las que tienen expansión "Existe una clara relación entre acento, entonación y límites sintagmáticos. No obstante, la entonación del pretonema no se caracteriza, ni por la alineación de los picos tonales con los acentos (overshooting), ni por el establecimiento de fronteras prosódicas nítidas entre el núcleo y la expansión del SN (2006: 13)".

De manera que las interrogativas analizadas se caracterizan por una subida tonal inicial que culmina en un pico máximo y se alinea "o con el límite sintagmático más fuerte, o con una sílaba próxima a dicho límite, esto es, o más frecuentemente con el final del SV, en las interrogativas sin expansión, o con el final del SN, en las interrogativas con expansión en el sujeto" (2006: 13).

Dorta et al. (2007) realizaron un trabajo análogo al anterior, pero esta vez haciendo una comparación entre la voz femenina y masculina de la isla de Tenerife y entre la modalidad interrogativa y declarativa. Encontraron resultados similares a los mencionados en Dorta (2006), esto es, las oraciones con y sin expansión en ambas modalidades y en ambos sexos se caracteriza por la existencia de una trayectoria ascendente de la F0 que culmina en un pico máximo que no se alinea con el acento, sino con el límite sintagmático más fuerte o con una sílaba próxima a dicho límite.

Asimismo, Cuevas et al. (2007), en el marco de AMPER-Astur, realizaron un trabajo con un objetivo similar al de los trabajos citados. Analizaron la modalidad interrogativa y declarativa en oraciones SVO con expansión en el sujeto con diferente tipología acentual en cuatro informantes asturianas de la zona central. Los 
resultados volvieron a mostrar que los picos asociados al acento fonológico tienden a la posrealización (una o dos sílabas) con el fin de marcar fronteras sintagmáticas fuertes, excepto solo cuando el límite sintagmático entre sujeto y verbo lo establece una oxítona. Solamente en este caso hay un alineamiento tonal, esto es, el acento fonológico se alinea con la vocal tónica.

Los estudios en español que han analizado la importancia de la relación entre picos tonales y fronteras sintagmáticas en el marco de AMPER tienden a mostrar que esta relación es sólida. Sin embargo, dado al escaso número de estudios y la parcialidad de los mismos ${ }^{5}$ no se puede confirmar este modelo como general en el español. Además, las investigaciones se han basado en las prominencias tonales independientemente de que existan o no diferencias mínimas perceptivas (DMP). En este trabajo, en cambio, consideramos solo aquellos picos en los que hay DMP basándonos en el umbral de 1,5 st (Rietveld y Gussenhoven 1985): si las diferencias son inferiores a este umbral, el oído no las detecta y por consiguiente no son funcionales (Pamies et al. 2002). Así, pues, el objetivo del presente trabajo es analizar la validez de la hipótesis demarcativa en oraciones declarativas e interrogativas en voces femeninas y masculinas colombianas (Medellín y Bogotá) y canarias (Tenerife y Gran Canaria). $\mathrm{Si}$, en términos generales, los picos máximos se alinean con vocales átonas y con fronteras sintagmáticas podremos sugerir que la hipótesis demarcativa se confirma en el habla canaria y colombiana al menos en el tipo de corpus formal que analizamos.

\section{Metodología}

La metodología del trabajo sigue las pautas establecidas en el proyecto AMPER internacional (para mayor información véase Martínez Celdrán y Fernández Planas 2006) en todos sus aspectos.

\subsection{Informantes y corpus}

Se analizan las emisiones de ocho informantes sin estudios de la zona urbana de cuatro puntos de encuesta: Medellín y Bogotá (Colombia) y Tenerife y Las Palmas de Gran Canaria (Islas Canarias). En cada punto urbano se entrevistó a un hombre y una mujer con edades comprendidas en el rango 25-45 años.

De forma general, el proyecto AMPER considera cuatro corpus: el fijo o formal ad hoc, el situacional, el Map task y la conversación informal (Contini 2005). El corpus analizado en el presente estudio es el denominado "corpus fijo" o ad hoc en el que se controlan diferentes variables. Este corpus se reparte entre tres estructuras: oraciones simples ( $\mathrm{S}+\mathrm{V}+\mathrm{O}$ : el saxofón se toca con emoción), oraciones con expansión en el sujeto $(\mathrm{S}+\mathrm{EXP}+\mathrm{V}+\mathrm{O}$ : la guitarra italiana se toca con paciencia) y oraciones con expansión en el objeto ( $\mathrm{S}+\mathrm{V}+\mathrm{O}+\mathrm{EXP}$ : la máquina se toca con pánico práctico).

\footnotetext{
Téngase en cuenta que en los trabajos citados realizados en el marco de AMPER unos analizan solo las oraciones en la modalidad interrogativa (Dorta 2006) o declarativas (Pamies et al. 2007), o analizan solo voces femeninas (Dorta 2006; Pamies et al. 2007; Cuevas et al. 2007). Solamente en dos trabajos se ha analizado la modalidad declarativa y la interrogativa (Dorta et al. 2007 y Cuevas et al. 2007). Por otra parte, estos estudios se han hecho con solo uno o dos hablantes o, en el caso de Cuevas et al. (2007), con cuatro, si bien es cierto que en el marco de AMPER se consideran representativos de las zonas analizadas.
} 
Como puede verse en los ejemplos ilustrativos, los sintagmas inicial y final y la expansión del sujeto y del objeto son trisílabos con una tipología acentual oxítona, paroxítona o proparoxítona; el sintagma central, en cambio, permanece invariable (acento paroxítono). Todas las combinaciones posibles dan como resultado 63 oraciones en cada modalidad (enunciativa e interrogativa absoluta) en español. Este corpus se presenta a los informantes de forma aleatoria y se graba un mínimo de tres repeticiones de cada una de las oraciones que se analizarán posteriormente.

Para el presente estudio, de las 63 oraciones de la modalidad declarativa seleccionamos 27 (9 de cada estructura oracional; el criterio de selección para las oraciones con expansión se basó en que el nombre y su respectiva expansión debían coincidir en la estructura acentual) y la misma cantidad para las interrogativas, es decir, un total de 54 oraciones de cada informante. Teniendo en cuenta que de cada oración tenemos 3 repeticiones (162 oraciones) pronunciadas por una mujer y un hombre de cada una de las 4 localidades analizadas (8 informantes), el total asciende a 1296 oraciones, 648 declarativas y otras tantas interrogativas tomadas del corpus fijo del proyecto AMPER-Col y AMPER-Can. Una vez seleccionadas las oraciones, se analizó el tonema y el pretonema en función de la tipología acentual dentro de cada estructura oracional generando así combinaciones oxítonas, paroxítonas o proparoxítonas.

\subsection{Análisis acústico}

Utilizamos los programas Goldwave 4.25 para la digitalización y conversión de ficheros de sonido (.wav) y MatLab -Matriz Laboratory- ${ }^{6}$ para el análisis acústico. Las rutinas creadas en Matlab permiten obtener, a partir de la segmentación de las vocales en el oscilograma, tres valores de F0 de cada núcleo silábico (en el inicio, en el medio y en el final), además de los valores de duración e intensidad. En el presente trabajo nos centramos en el primero de estos parámetros.

Hemos considerado los picos tonales definidos como la máxima prominencia tonal entre dos valles. Así, al comparar el tono de un pico con el del valle precedente o siguiente debe haber diferencias iguales o superiores a 1,5 St.; en caso contrario, la prominencia tonal no se toma como pico.

\section{Resultados}

Presentaremos los resultados en tres grandes apartados: en el primero veremos los relacionados con las oraciones sin expansión; en el segundo, los de las oraciones con expansión en el sujeto; y en el tercero, los de las oraciones con expansión en el objeto. En cada uno de ellos se verá, en primer lugar, los resultados generales teniendo en cuenta los picos tonales, acentos y fronteras sintagmáticas en función de la modalidad, la localidad y el género. A continuación, nos centramos específicamente en la relación pico/acento y, finalmente, atendemos a la relación entre picos máximos y fronteras sintagmáticas.

Licencia $\mathrm{n}^{\circ} 256105$ en Canarias y Licencia $\mathrm{n}^{\circ} 878004$ del laboratorio de fonética de la Universidad de Antioquia en Colombia. Para más información sobre el programa y las subrutinas creadas por el Centre de Dialectologie de Grenoble, véase Fernández Planas (2005); sobre la adaptación realizada por el grupo Amper-Astur, véase López Bobo et al. 2007. 


\subsection{Oraciones sin Expansión}

\subsubsection{Cuestiones generales}

Tomando las oraciones en conjunto, los datos (figuras ${ }^{7} 1-2$ y Tabla $1^{8}$ ) indican que las oraciones interrogativas presentan más picos tonales que las declarativas $(53,75 \%$ y $46,25 \%$, respectivamente). Observando las modalidades de forma independiente, encontramos que en ambas las oraciones colombianas tienen un porcentaje ligeramente superior respecto de las canarias: Medellín 29,73\% y 27,91\%; Bogotá $24,32 \%$ y $25,58 \%$; Tenerife $21,62 \%$ y $23,27 \%$; Gran Canaria $24,32 \%$ y $23,36 \%$, en declarativas e interrogativas, respectivamente. Por otra parte, en las declarativas, los hombres presentan más picos tonales $(56,75 \%)$ que las mujeres; en cambio, en las oraciones interrogativas se invierte el patrón, aunque la diferencia es muy leve $(51,17 \%$ en mujeres). En cuanto a la sincronización con el acento, en las declarativas el $97,27 \%$ de picos se sincroniza con vocal átona, mientras que en las interrogativas el porcentaje desciende en un 30\% (60,47\%). Sin embargo, como se verá a continuación, de los picos que recaen en la tónica, en las oraciones declarativas el total coincide con una frontera sintagmática; en las interrogativas, en cambio, esto sucede en solo un $23,30 \%$ y en el resto de los casos está muy próximo a ella. En cualquier caso, la sincronización se genera más por la relación pico/frontera sintagmática que pico/ acento. 
Figura 1. Modalidad declarativa en función del género, la tipología acentual y los sintagmas en las oraciones sin expansión 9 .

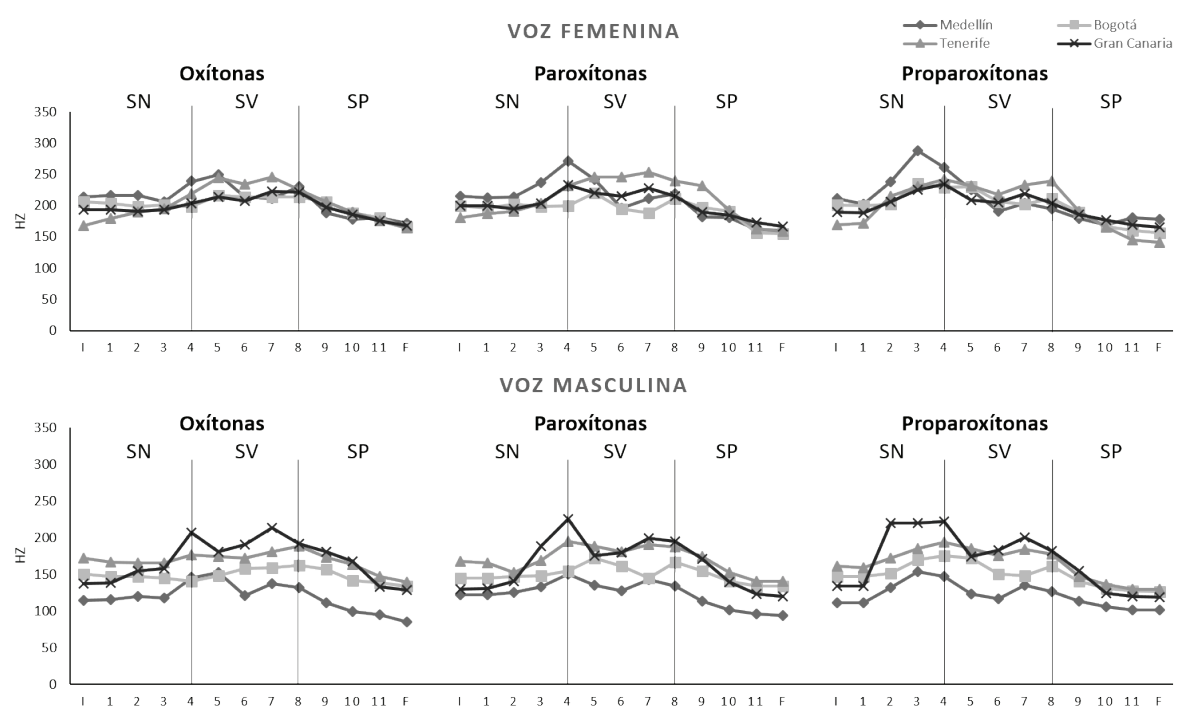

Figura 2. Modalidad interrogativa en función del género, la tipología acentual y los sintagmas en las oraciones sin expansión.

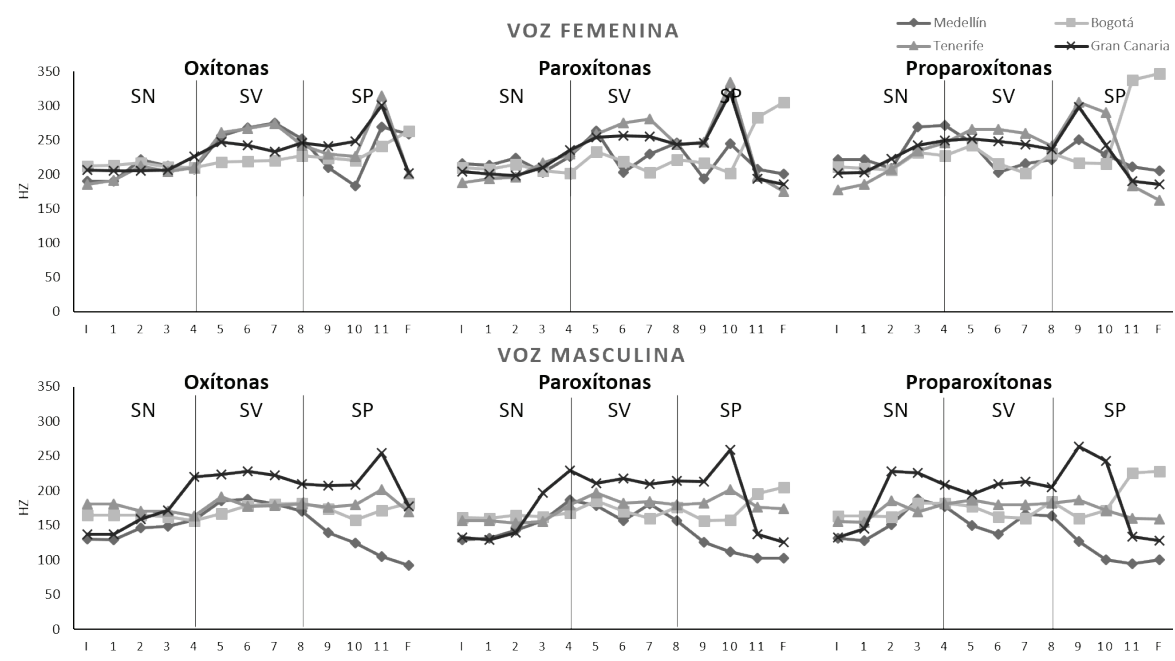

$9 \quad$ Las figuras representan la media de la frecuencia fundamental del pretonema y el tonema con la misma tipología acentual. 
Tabla 1. Oraciones declarativas e interrogativas, en función de los picos máximos, la tipología acentual, la sílaba, el acento y la frontera sintagmática.

\begin{tabular}{|c|c|c|c|c|c|c|c|c|c|c|c|c|c|c|c|c|c|}
\hline \multirow{5}{*}{$\begin{array}{l}\text { Tipología } \\
\text { acentual }\end{array}$} & & \multicolumn{16}{|c|}{ DATOS GENERALES ORACIONES $\mathrm{S}+\mathrm{V}+\mathrm{O}$} \\
\hline & & \multicolumn{4}{|c|}{ Valor en $\mathrm{HZ}$} & \multicolumn{4}{|c|}{$\begin{array}{l}\text { Número de } \\
\text { sílaba }\end{array}$} & \multicolumn{4}{|c|}{ Acento } & \multicolumn{4}{|c|}{$\begin{array}{c}\text { Frontera } \\
\text { sintagmática }\end{array}$} \\
\hline & & \multicolumn{2}{|c|}{ M } & \multicolumn{2}{|c|}{$\mathbf{H}$} & \multicolumn{2}{|c|}{$\mathbf{M}$} & \multicolumn{2}{|c|}{$\mathbf{H}$} & \multicolumn{2}{|c|}{$\mathbf{M}$} & \multicolumn{2}{|c|}{$\mathbf{H}$} & \multicolumn{2}{|c|}{$\mathbf{M}$} & \multicolumn{2}{|c|}{$\mathbf{H}$} \\
\hline & Pico & D & I & $\mathbf{D}$ & I & D & $\mathbf{I}$ & D & I & D & I & D & I & D & I & D & I \\
\hline & \multicolumn{17}{|c|}{ Medellín } \\
\hline $\mathrm{O}$ & $\mathrm{PMx} 1$ & 249 & 275 & 152 & 188 & 5 & 7 & 5 & 6 & A & A & A & $\mathrm{T}$ & ISV & FSV & ISV & PSV \\
\hline $\mathrm{O}$ & PMx2 & 231 & 269 & 138 & & 8 & 11 & 7 & & A & $\mathrm{T}$ & A & & ISP & FSP & FSV & \\
\hline $\mathrm{P}$ & PMx1 & 271 & 263 & 150 & 186 & 4 & 6 & 4 & 4 & A & $\mathrm{T}$ & A & A & FSN & PSV & FSN & FSN \\
\hline $\mathrm{P}$ & PMx2 & 218 & 246 & 142 & 180 & 8 & 8 & 7 & 7 & A & A & A & A & ISP & ISP & FSV & FSV \\
\hline $\mathrm{P}$ & PMx3 & & 245 & & & & 10 & & & & $\mathrm{~T}$ & & & & PSP & & \\
\hline $\operatorname{Pr}$ & PMx1 & 288 & 271 & 154 & 187 & 3 & $3=4$ & 3 & 3 & A & A & A & A & PSN & PSN & PSN & PSN \\
\hline $\operatorname{Pr}$ & $\mathrm{PMx} 2$ & & 251 & 135 & 165 & & 9 & 7 & 7 & & $\mathrm{~T}$ & $\mathrm{~A}$ & A & & ISSP & FSV & FSV \\
\hline \multicolumn{18}{|c|}{ Bogotá } \\
\hline $\mathrm{O}$ & PMx1 & 216 & 241 & 162 & 182 & 5 & 11 & 8 & 8 & A & $\mathrm{T}$ & A & A & ISV & FSP & ISP & ISP \\
\hline $\mathrm{P}$ & PMx1 & 221 & 233 & 172 & 185 & 5 & 5 & 5 & 5 & A & A & A & A & ISV & ISV & ISV & ISV \\
\hline $\mathrm{P}$ & $\mathrm{PMx} 2$ & 211 & 282 & 167 & 196 & 8 & 11 & 8 & 11 & A & A & A & A & ISP & FSP & ISP & FSP \\
\hline Pr & PMx1 & 236 & 242 & 175 & 182 & 3 & 5 & 4 & 4 & A & A & A & A & PSN & ISV & FSN & FSN \\
\hline $\operatorname{Pr}$ & PMx2 & & 337 & 161 & 184 & & 11 & 8 & 8 & & A & A & A & & FSP & ISP & ISP \\
\hline $\operatorname{Pr}$ & PMx3 & & & & 226 & & & & 11 & & & & A & & & & FSP \\
\hline \multicolumn{18}{|c|}{ Tenerife } \\
\hline $\mathrm{O}$ & PMx1 & 245 & 273 & 188 & 191 & 7 & 7 & 8 & 5 & A & A & A & A & FSV & FSV & ISP & ISV \\
\hline $\mathrm{O}$ & PMx2 & & 314 & 188 & & & 11 & 8 & & & $\mathrm{~T}$ & A & & & FSP & PSP & \\
\hline $\mathrm{P}$ & PMx1 & 253 & 280 & 195 & 197 & 7 & 7 & 4 & 5 & A & A & A & A & FSV & FSV & FSN & ISV \\
\hline $\mathrm{P}$ & PMx2 & & 334 & & 201 & & 10 & & 10 & & $\mathrm{~T}$ & & $\mathrm{~T}$ & & PSP & & PSP \\
\hline $\operatorname{Pr}$ & PMx1 & 242 & 266 & 194 & 187 & 4 & 5 & 4 & 5 & A & A & A & A & FSN & ISV & FSN & ISV \\
\hline $\operatorname{Pr}$ & $\mathrm{PMx} 2$ & 239 & 304 & & & 8 & 9 & & & A & $\mathrm{T}$ & & & ISP & ISSP & & \\
\hline \multicolumn{18}{|c|}{ Gran Canaria } \\
\hline $\mathrm{O}$ & PMx1 & 222 & 247 & 206 & 228 & 7 & 5 & 4 & 6 & A & A & $\mathrm{T}$ & $\mathrm{T}$ & FSV & ISV & FSN & PSV \\
\hline $\mathrm{O}$ & $\mathrm{PMx} 2$ & & 300 & 213 & 254 & & 11 & 7 & 11 & & $\mathrm{~T}$ & A & $\mathrm{T}$ & & FSP & FSV & FSP \\
\hline $\mathrm{P}$ & PMx1 & 233 & 318 & 226 & 229 & 4 & 11 & 4 & 4 & A & A & A & A & FSN & FSP & FSN & FSN \\
\hline $\mathrm{P}$ & PMx2 & & & 200 & 259 & & & 7 & 10 & & & A & $\mathrm{T}$ & & & FSV & PSP \\
\hline $\operatorname{Pr}$ & PMx1 & 234 & 298 & 222 & 227 & 4 & 9 & 4 & 2 & A & $\mathrm{T}$ & A & $\mathrm{T}$ & FSN & ISSP & FSN & ISSN \\
\hline $\operatorname{Pr}$ & $\mathrm{PMx} 2$ & & & 200 & 264 & & & 7 & 9 & & & A & $\mathrm{T}$ & & & FSV & ISSP \\
\hline
\end{tabular}




\subsubsection{Relación pico/acento}

La Tabla 2 muestra que en las oraciones declarativas hay un número mayor de picos en el pretonema que en el tonema, independientemente de la tipología acentual. En cambio, en las oraciones interrogativas hay una distribución similar.

Tabla 2. Alineación en porcentajes de la relación pico/acento léxico en función de la tipología acentual en oraciones sin expansión.

\begin{tabular}{|c|c|c|c|c|c|c|c|}
\hline & \multicolumn{7}{|c|}{ ALINEACIÓN PICO/ACENTO ORACIONES S+V+O } \\
\hline & & \multicolumn{3}{|c|}{ Declarativa } & \multicolumn{3}{|c|}{ Interrogativa } \\
\hline & & Pretonema & Tonema & Total & Pretonema & Tonema & Total \\
\hline \multirow{4}{*}{$\mathbf{O}$} & Pretónica & 0 & 0 & 0 & 0 & 0 & 0 \\
\hline & Tónica & 2,70 & 0 & 2,70 & 4,65 & 11,63 & 16,28 \\
\hline & Postónica & 18,92 & 0 & 18,92 & 9,30 & 0 & 9,30 \\
\hline & Pospostónica & 0 & 10,81 & 10,81 & 0 & 2,33 & 2,33 \\
\hline \multicolumn{2}{|c|}{ Total } & 21,62 & 10,81 & 32,43 & 13,95 & 13,96 & 27,91 \\
\hline \multirow{4}{*}{$\mathbf{P}$} & Pretónica & 0 & 0 & 0 & 0 & 0 & 0 \\
\hline & Tónica & 0 & 0 & 0 & 2,33 & 9,30 & 11,63 \\
\hline & Postónica & 21,62 & 0 & 21,62 & 9,3 & 6,98 & 16,28 \\
\hline & Pospostónica & 5,41 & 8,11 & 13,52 & 6,98 & 2,33 & 9,31 \\
\hline \multicolumn{2}{|c|}{ Total } & 27,03 & 8,11 & 35,14 & 18,61 & 18,61 & 37,22 \\
\hline \multirow{4}{*}{$\operatorname{Pr}$} & Pretónica & 0 & 0 & 0 & 6,98 & 0 & 6,98 \\
\hline & Tónica & 0 & 0 & 0 & 2,33 & 9,30 & 11,63 \\
\hline & Postónica & 13,51 & 0 & 13,51 & 6,98 & 4,65 & 11,63 \\
\hline & Pospostónica & 13,51 & 5,41 & 18,92 & 2,33 & 2,33 & 4,66 \\
\hline \multicolumn{2}{|c|}{ Total } & 27,02 & 5,41 & 32,43 & 18,62 & 16,28 & 34,90 \\
\hline
\end{tabular}

En el pretonema de las declarativas, ningún pico de las paroxítonas y proparoxítonas se sincroniza con vocal tónica, ya que se desplaza hacia la derecha alternando entre la postónica y la pos-postónica. En las oraciones con acento oxítono, aunque el pico coincide con un porcentaje bajo de tónicas, se imponen las átonas y, a diferencia de los otros dos acentos, la pos-realización se da en la sílaba inmediatamente siguiente. En el tonema de esta modalidad, independientemente de la tipología acentual, cuando hay un pico se desplaza dos sílabas.

En cuanto a las interrogativas, en el pretonema de los tres acentos se observa un bajo porcentaje de picos sincronizados con la vocal tónica en comparación con las átonas. El pico se desplaza hacia la derecha, alternando entre la postónica y la pospostónica. En el tonema de esta modalidad, la sincronización entre pico/tónica y pico/ 
átona es similar cuando se trata de paroxítonas y proparoxítonas, mientras que en las oxítonas hay una mayor distribución en la sincronización pico/tónica.

\subsubsection{Relación pico/frontera sintagmática}

La Figura 3 ilustra que los picos coinciden con una frontera sintagmática (FS) en la mayoría de los casos, de forma esporádica, muy próximo a ella. En el pretonema de las oraciones declarativas, la sincronización se produce de la manera siguiente: FSN (29,72\%), ISV (13,52\%) y FSV (24,33\%); en el tonema el pico coincide con el ISP $(24,33 \%)$. En las oraciones interrogativas, la sincronización en el pretonema se da de la manera siguiente: al FSN $(6,98 \%)$, al ISV $(18,61 \%)$ y al FSV $(11,63 \%)$ o muy próximo al SN (2,5\%) o al SV (3,75\%). En el tonema, a diferencia de las declarativas, encontramos más movimientos tonales al ISP (6,99\%), al FSP $(23,26 \%)$ o muy próximo al SP $(9,3 \%)$. Al tomar las oraciones en conjunto, observamos que la mayor prominencia tonal marca la frontera FSN/ISV, FSV/ISP y solamente en las interrogativas al FSP.

Figura 3. Alineación picos/FS en oraciones sin expansión.

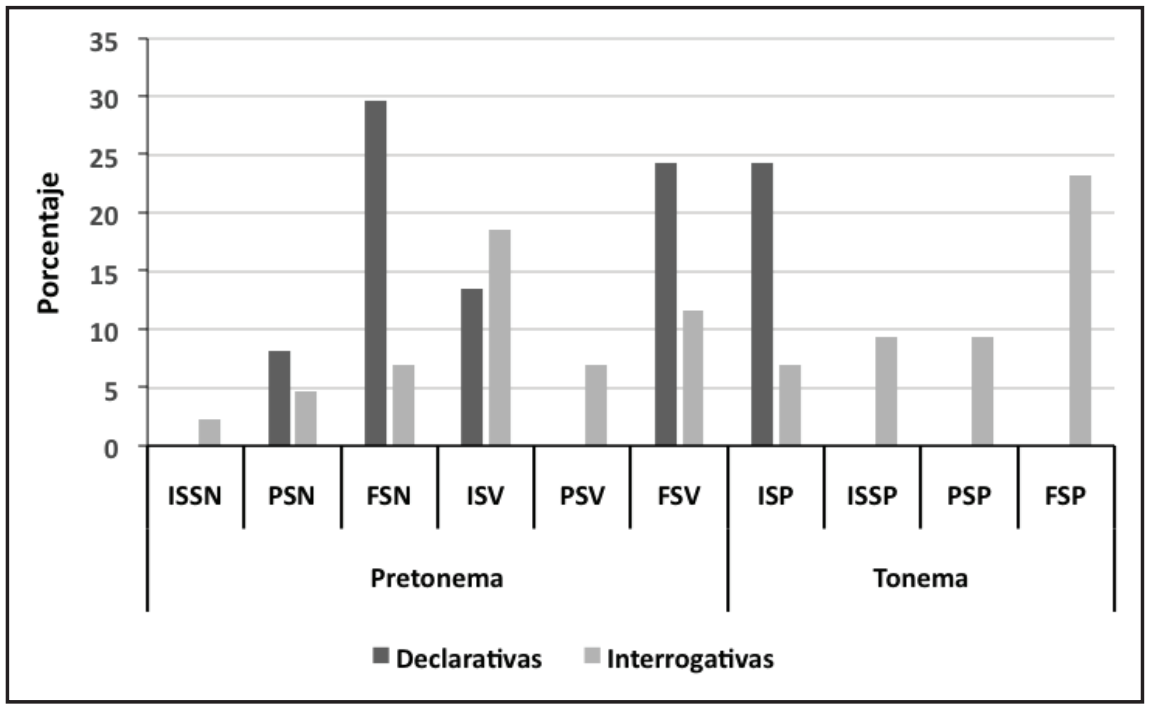

Tomando el conjunto de los datos (véanse las tablas 1 y 2 y la Figura 3 ) podemos determinar que las vocales átonas que se sincronizan con picos también lo hacen con la frontera sintagmática, independientemente de la tipología acentual, o con una frontera próxima a ella, como sucede en el 8,11\% de proparoxítonas de las oraciones declarativas en donde recae en la postónica del pretonema; este resultado se presenta solamente en el habla colombiana ${ }^{10}$. En esta modalidad, el 2,7\% de los picos de las

10 En la mujer y el hombre de Medellín, pero solo en la mujer de Bogotá. 
oxítonas que se alinean con tónica, también lo hacen con una frontera sintagmática, esto es, con el $\mathrm{FSN}^{11}$. En las oraciones interrogativas se da un patrón similar: el $11,63 \%$ (Colombia 4,66\% ${ }^{12}$; Canarias $6,97 \%{ }^{13}$ ) de las oxítonas que en el tonema se alinean con el pico, lo hacen también con una frontera sintagmática, esto es, con el FSP o con una frontera próxima a ella; por tanto, esta alineación se genera por una relación entre pico y frontera y no entre pico y acento.

\subsection{Oraciones con expansión en el sujeto}

\subsubsection{Cuestiones generales}

Los datos (figuras 4-5 y Tabla $3^{14}$ ) muestran que en este tipo de oraciones las interrogativas vuelven a presentar más movimientos tonales que las declarativas (60,75\% y 39,25\%, respectivamente). Asimismo, ambas modalidades vuelven a registrar un porcentaje mayor de picos en Colombia que en Canarias (Medellín $28,57 \%$ y $27,69 \%$; Bogotá 33,33\% y 32,33\%; Tenerife $16,66 \%$ y 15,38\%; Gran Canaria $21,42 \%$ y $24,60 \%$, en declarativas e interrogativas, respectivamente). Por otra parte, en las dos modalidades el porcentaje de prominencias tonales significativas es ligeramente mayor en los hombres que en las mujeres $(52,38 \% \mathrm{y}$ $47,65 \%$ en declarativas de ambos sexos y $50,79 \%$ y $49,23 \%$ en interrogativas). En cuanto a la sincronización del pico, en las declarativas el 100\% coincide con vocal átona, mientras que en las interrogativas el porcentaje baja al 72,31\%. Sin embargo, como se verá a continuación, del $27,69 \%$ de picos que recaen en la tónica, el 18,46\% también coincide con frontera sintagmática y el resto está muy próximo a ella; por tal motivo, la sincronización se genera más por la relación pico/frontera sintagmática que pico/acento.

\footnotetext{
Sucede así en el hombre de Gran Canaria.

2 Mujeres de Medellín y Bogotá.

13 Mujer y hombre de Gran Canaria y mujer de Tenerife.

14 PEX = penúltima de expansión; IEX = inicio de expansión; FSUN = final sustantivo sintagma nominal; ISUP = inicio sustantivo sintagma preposicional; PSUN = penúltima sustantivo sintagma nominal.
} 
Figura 4. Modalidad declarativa en función del género, la tipología acentual y los sintagmas en las oraciones con expansión en el sujeto.

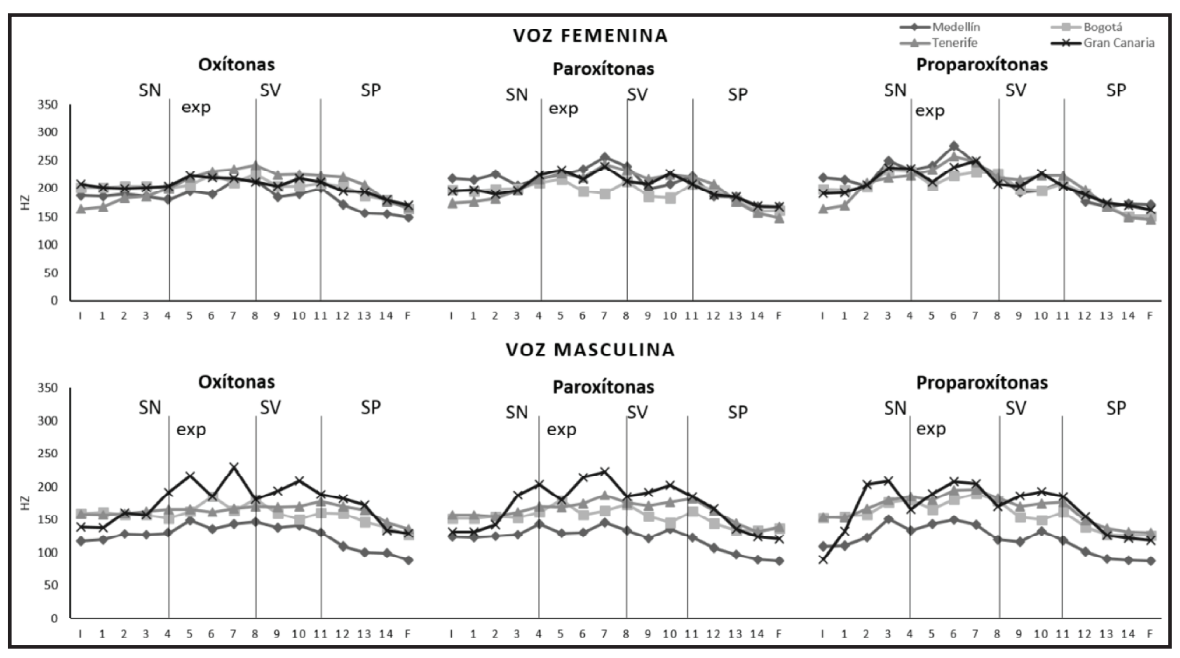

Figura 5. Modalidad interrogativa en función del género, la tipología acentual y los sintagmas en las oraciones con expansión en el sujeto.

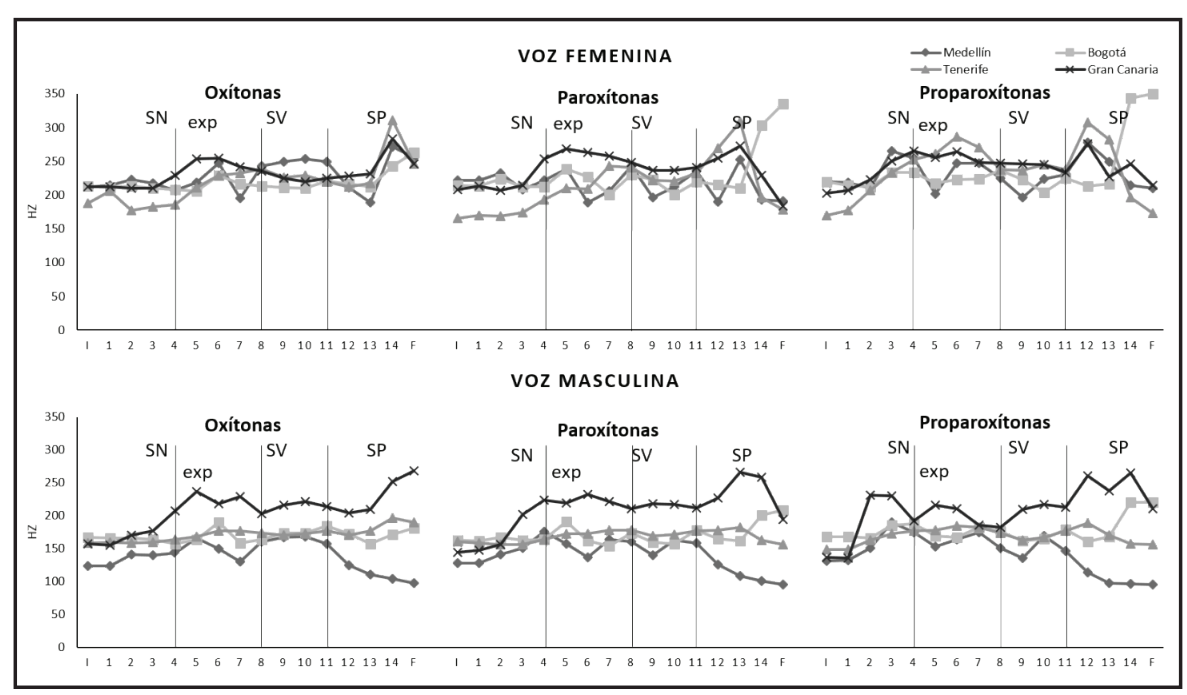


LÍMITE PROSÓDICO Y SINTAGMÁTICO: ESTUDIO COMPARATIVO ENTRE ZONAS DE COLOMBIA E ISLAS CANARIAS (ESPAÑA)

Tabla 3. Oraciones declarativas e interrogativas, en función de los picos máximos, la tipología acentual, la sílaba, el acento y la frontera sintagmática.

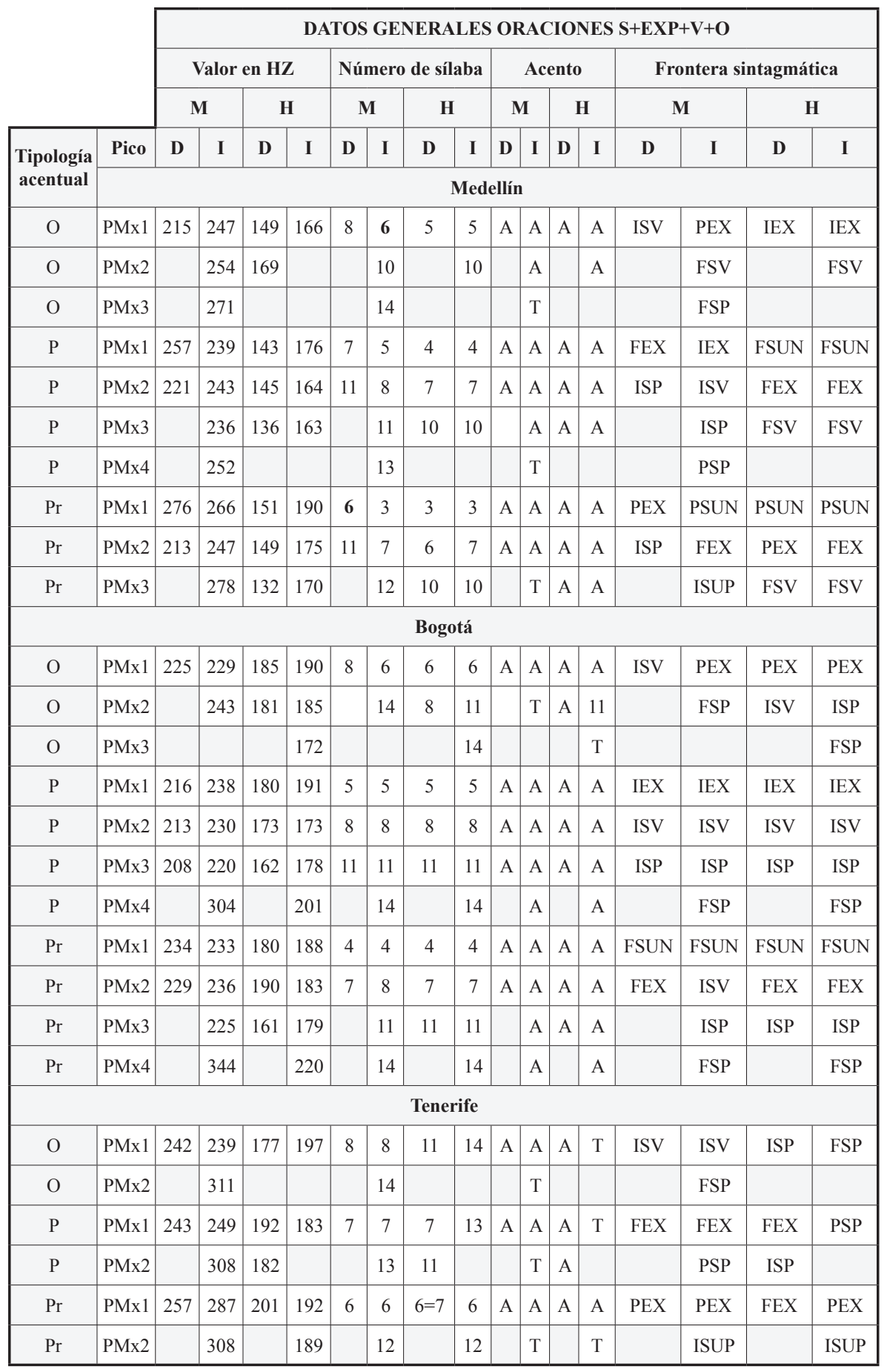




\begin{tabular}{|c|l|l|l|c|c|c|c|c|c|c|c|c|c|c|c|c|c|}
\hline \multicolumn{10}{|c|}{ Gran Canaria } \\
\hline O & PMx1 & 222 & 254 & 177 & 237 & 5 & 6 & 11 & 5 & A & A & A & A & IEX & PEX & ISP & IEX \\
\hline O & PMx2 & & 284 & & 222 & & 14 & & 10 & & T & A & & FSP & & FSV \\
\hline O & PMx3 & & & 252 & & & & 14 & & & T & & & & FSP \\
\hline P & PMx1 & 240 & 268 & 187 & 233 & 7 & 5 & 7 & 6 & A & A & A & T & FEX & IEX & FEX & PEX \\
\hline P & PMx2 & 226 & 273 & & 266 & 10 & 13 & & 13 & A & A & & T & FSV & PSP & & PSP \\
\hline Pr & PMx1 & 236 & 266 & 196 & 230 & 4 & 4 & 7 & 3 & A & A & A & A & FSUN & FSUN & FEX & PSUN \\
\hline Pr & PMx2 & 250 & 276 & & 217 & 7 & 12 & & 5 & A & T & & T & FEX & ISUP & & IEX \\
\hline$P r$ & PMx3 & 227 & 246 & & 260 & 10 & 14 & & 12 & A & A & & T & FSV & FSP & & ISUP \\
\hline$P r$ & PMx4 & & & 265 & & & & 14 & & & A & & & & FSP \\
\hline
\end{tabular}

\subsubsection{Relación pico/acento}

La Tabla 4 muestra que en el pretonema tiende a haber un número mayor de picos que en el tonema, independientemente de la modalidad oracional o de la tipología acentual. En el pretonema de las declarativas ningún pico se sincroniza con vocal tónica, ya que se desplaza hacia la derecha alternando entre la postónica y la postpostónica, excepto en las oxítonas en las que la posrealización se da solamente en la sílaba inmediatamente siguiente. El tonema en esta modalidad presenta el mismo patrón acentual que las oraciones sin expansión, esto es, independientemente de la tipología acentual, el pico — cuando se da— se desplaza dos sílabas a la derecha.

Tabla 4. Alineación en porcentajes de la relación pico/acento léxico en función de la tipología acentual en oraciones con expansión en el sujeto.

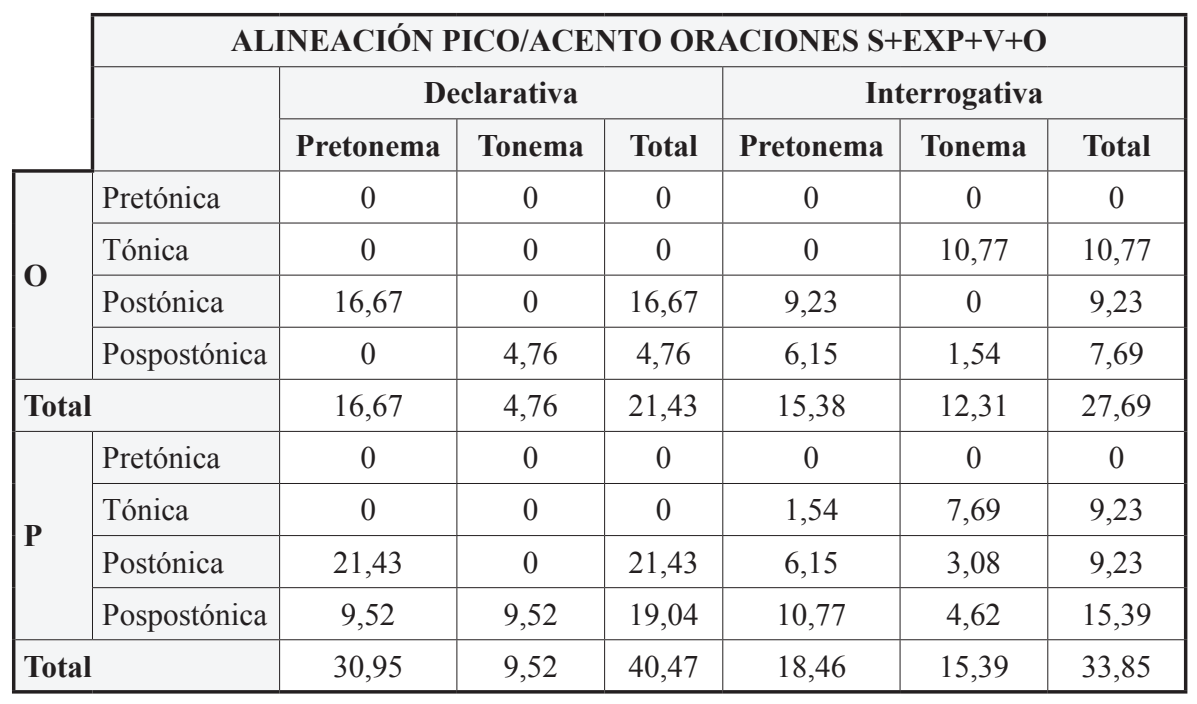




\begin{tabular}{|c|c|c|c|c|c|c|c|}
\hline \multirow{4}{*}{ Pr } & Pretónica & 0 & 0 & 0 & 1,54 & 0 & 1,54 \\
\hline & Tónica & 0 & 0 & 0 & 0 & 7,69 & 7,69 \\
\hline & Postónica & 14,29 & 0 & 14,29 & 10,77 & 0 & 10,77 \\
\hline & Pospostónica & 19,05 & 4,76 & 23,81 & 9,23 & 9,23 & 18,46 \\
\hline \multicolumn{2}{|c|}{ Total } & 33,34 & 4,76 & 38,10 & 21,54 & 16,92 & 38,46 \\
\hline
\end{tabular}

En el pretonema de las interrogativas se da sincronización con la vocal tónica cuando se trata de paroxítonas; sin embargo, el porcentaje es muy bajo (1,54\%) en comparación con el de las átonas (16,92\%). El desplazamiento de los picos alterna entre la postónica y la postpostónica en las tres tipologías acentuales. En el tonema de esta modalidad, la sincronización de pico/tónica es superior a la de pico/átona, pero solamente en las oxítonas; en las paroxítonas la distribución es similar y en las proparoxítonas la sincronización pico/átona es superior a pico/tónica. Sin embargo, tomando los datos en conjunto sin diferenciar entre pretonema y tonema, los datos muestran que existe una clara tendencia a que el pico se sincronice con vocal átona al desplazarse hacia la derecha generando, por tanto, su pos-realización, hecho que se produce independientemente de la modalidad y de la tipología acentual.

\subsubsection{Relación picos/fronteras sintagmáticas}

La Figura 6 muestra que las oraciones con expansión en el sujeto presentan un patrón similar al de las oraciones sin expansión, es decir, los picos coinciden con una frontera sintagmática en la mayoría de los casos, o de forma esporádica muy próxima a ella. En el pretonema de las declarativas, el pico coincide con el FSN (28,58\%), ISV $(14,28 \%)$ y final del SV $(9,52 \%)$ y, además, marca la frontera sintagmática débil, esto es, FSUN e IEX con un porcentaje similar (9,52\%); en el tonema coincide con el ISP (19,04\%). En las oraciones interrogativas, la sincronización de los picos con la frontera sintagmática se da en el FSN $(6,26 \%)$ y en el ISV y FSV con un porcentaje similar (7,81\%); además, marca la frontera sintagmática débil, esto es, FSUN (6,25\%) e IEX (10,94\%). En el tonema, a diferencia de las declarativas, encontramos más movimientos tonales al ISP $(9,38 \%)$, al FSP (20,32\%) o muy próximo al SP (7,81\%). 
Figura 6. Alineación picos/FS en oraciones con expansión en el sujeto.

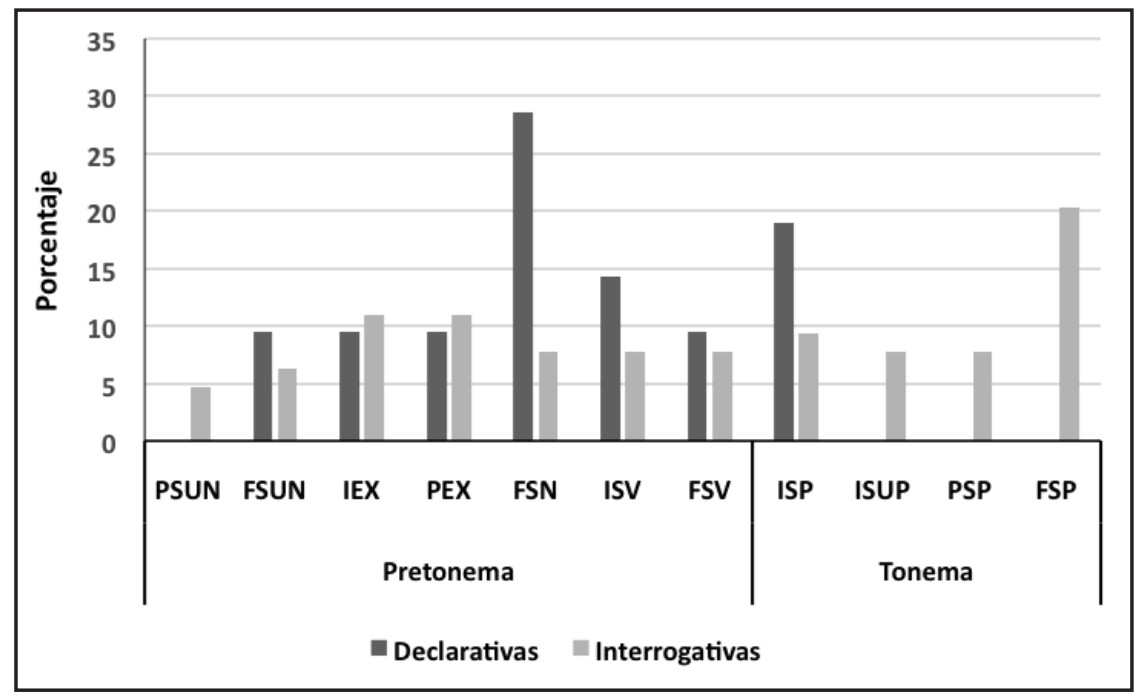

Al tomar las oraciones en conjunto, encontramos que hay un alto porcentaje de picos que señala invariablemente la frontera fuerte SN/SV y SV/SP y, como en las oraciones sin expansión, el FSP se marca solo en las oraciones interrogativas. También, observamos que los picos tonales se sincronizan con la frontera sintagmática débil FSUN/IEX.

Si observamos los datos de las tablas 3 y 4 y la Figura 6, podemos determinar que las vocales átonas que se sincronizan con picos también lo hacen con la frontera sintagmática independientemente de la tipología acentual, excepto en el $9,5 \%{ }^{15}$ de declarativas y el $7,6 \%{ }^{16}$ de interrogativas proparoxítonas en que recae en la postónica del pretonema. La coincidencia entre picos y tónicas ${ }^{17}$ sucede solamente en las oraciones interrogativas y coincide con una frontera sintagmática o, en su defecto, con una sílaba próxima a dicha frontera. De esta manera, del 10,77\% de alineación en las oxítonas, la totalidad se da en el FSP; del 9,23\% de las paroxítonas ${ }^{18}$, el $7,69 \%$ está próxima al FSP y el resto al FEX; del 7,69\% de las proparoxítonas ${ }^{19}$, la totalidad está al ISUP. Por tanto, en términos generales, esta alineación se genera por una relación entre pico y frontera y no entre pico y acento.

\footnotetext{
15 Mujer y hombre de Medellín y mujer de Tenerife.

16 Mujer y hombre de Medellín y Tenerife, y solo hombre de Gran Canaria.

$17 \quad$ No se da en el hombre de Medellín.

18 Esto no se da en los informantes de Bogotá.

19 No se da en los informantes de Bogotá.
} 


\subsection{Oraciones con expansión en el objeto}

\subsubsection{Cuestiones generales}

En general, los datos (figuras 7-8 y Tabla 5) muestran que, en este tipo de oraciones, declarativas e interrogativas presentan una distribución de movimientos tonales similar (50,92\% y 49,08\%, respectivamente). Por otra parte, vuelve a evidenciarse que en Colombia se da mayor modulación tonal que en Canarias teniendo en cuenta que en las dos modalidades hay un porcentaje mayor de picos (Medellín 30,90\% y $30,19 \%$; Bogotá $27,27 \%$ y $32,07 \%$; Tenerife $20 \%$ y 22,64\%; Gran Canaria $21,81 \%$ y $15,1 \%$, en declarativas e interrogativas, respectivamente). En cuanto a la distribución porcentual por sexos, en las declarativas se reparten los picos al 50\% y en las interrogativas los hombres solo registran un ligero porcentaje por encima de las mujeres $(52,82 \%$ frente a $47,18 \%)$. En lo que respecta a la sincronización de los picos, en las declarativas un $94,44 \%$ se sincroniza con vocal átona y en las interrogativas un $66,1 \%$. Sin embargo, en la primera de estas modalidades, el $100 \%$ de picos que recaen en la tónica también coinciden con frontera sintagmática, mientras que en las interrogativas sucede lo mismo en el 22,64\% y en el resto coinciden con una frontera próxima. Por este motivo podemos volver a decir que la sincronización se genera más por la relación entre pico/frontera sintagmática que pico/acento.

Figura 7. Modalidad declarativa en función del género, la tipología acentual y los sintagmas en las oraciones con expansión en el objeto.

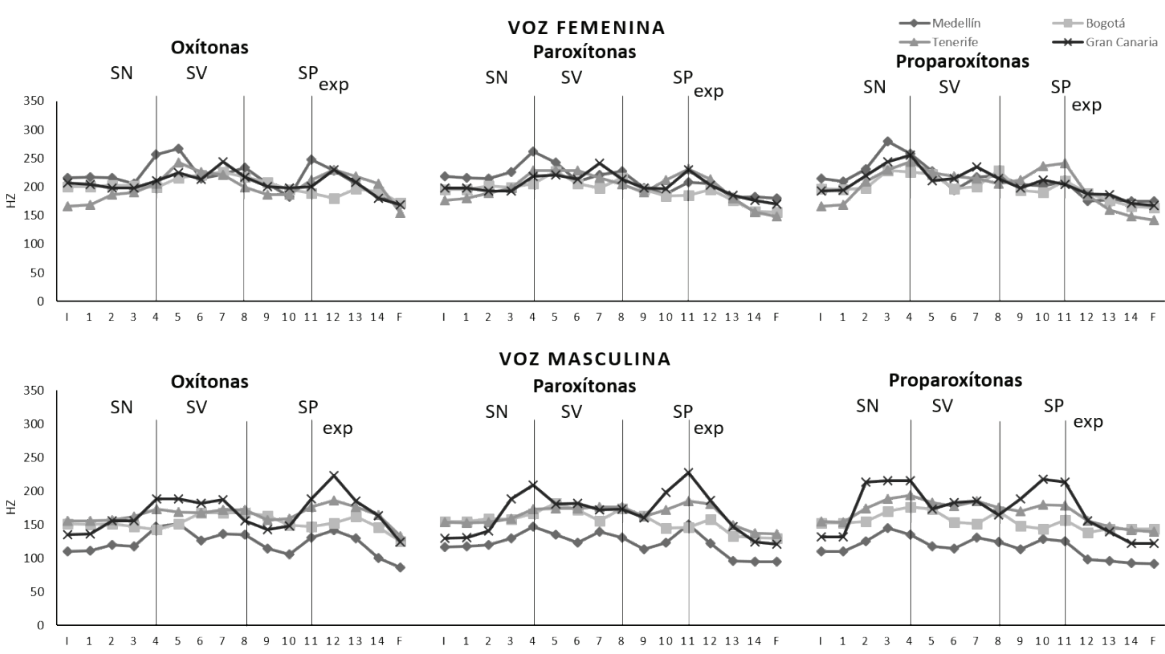


Figura 8. Modalidad interrogativa en función del género, la tipología acentual y los sintagmas en las oraciones con expansión en el objeto.

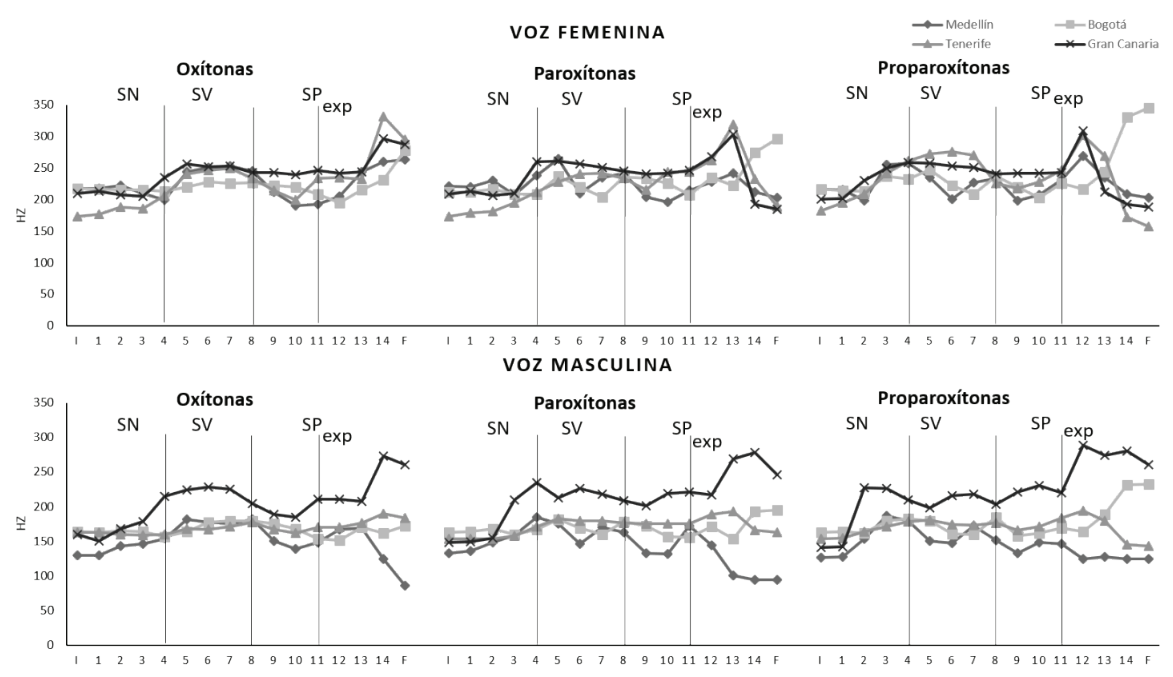

Tabla 5. Oraciones declarativas e interrogativas, en función de los picos máximos, la tipología acentual, la sílaba, el acento y la frontera sintagmática ${ }^{20}$.

\begin{tabular}{|c|c|c|c|c|c|c|c|c|c|c|c|c|c|c|c|c|c|}
\hline \multirow{5}{*}{$\begin{array}{l}\text { Tipología } \\
\text { acentual }\end{array}$} & & \multicolumn{16}{|c|}{ DATOS GENERALES ORACIONES S+V+O+EXP } \\
\hline & & \multicolumn{4}{|c|}{ Valor en $\mathbf{H z}$} & \multicolumn{4}{|c|}{$\begin{array}{l}\text { Número de } \\
\text { sílaba }\end{array}$} & \multicolumn{4}{|c|}{ Acento } & \multicolumn{4}{|c|}{ Frontera sintagmática } \\
\hline & & \multicolumn{2}{|c|}{ M } & \multicolumn{2}{|c|}{$\mathbf{H}$} & \multicolumn{2}{|c|}{ M } & \multicolumn{2}{|c|}{$\mathbf{H}$} & \multicolumn{2}{|c|}{ M } & \multicolumn{2}{|c|}{$\mathbf{H}$} & \multicolumn{2}{|c|}{ M } & \multicolumn{2}{|c|}{$\mathbf{H}$} \\
\hline & Pico & D & I & D & I & D & I & D & $\mathbf{I}$ & D & $\mathbf{I}$ & D & $\mathbf{I}$ & D & I & D & I \\
\hline & \multicolumn{17}{|c|}{ Medellín } \\
\hline $\mathrm{O}$ & PMx1 & 267 & 253 & 151 & 181 & 5 & 7 & 5 & 5 & A & A & A & A & ISV & FSV & ISV & ISV \\
\hline $\mathrm{O}$ & $\mathrm{PMx} 2$ & 234 & 244 & 136 & 169 & 8 & 13 & 7 & 13 & A & A & A & A & ISP & IEX & FSV & IEX \\
\hline $\mathrm{O}$ & PMx3 & 248 & 259 & 141 & & 11 & 15 & 12 & & $\mathrm{~T}$ & $\mathrm{~T}$ & A & & FSSP & FSP & IEX & \\
\hline $\mathrm{P}$ & PMx1 & 262 & 264 & 146 & 184 & 4 & 5 & 4 & 4 & A & A & A & A & FSN & ISV & FSN & FSN \\
\hline P & PMx2 & 228 & 242 & 139 & 170 & 8 & 8 & 7 & 7 & A & A & A & A & ISP & ISP & FSV & FSV \\
\hline $\mathrm{P}$ & PMx3 & 208 & 242 & 150 & 172 & 11 & 13 & 11 & 11 & A & $\mathrm{T}$ & A & A & FSSP & PEX & FSSP & FSSP \\
\hline $\operatorname{Pr}$ & PMx1 & 280 & 257 & 144 & 186 & 3 & 4 & 3 & 3 & A & A & A & A & PSN & FSN & PSN & PSN \\
\hline $\operatorname{Pr}$ & $\mathrm{PMx} 2$ & 219 & 233 & 131 & 172 & 8 & 8 & 7 & 7 & A & A & A & A & ISP & ISP & FSV & FSV \\
\hline $\operatorname{Pr}$ & PMx3 & & & 128 & 148 & & & 10 & 10 & & & A & A & & & PSV & PSV \\
\hline
\end{tabular}

${ }_{20} \mathrm{FSSP}=$ final sustantivo sintagma preposicional; PSSP $=$ penúltima sustantivo sintagma preposicional. 


\begin{tabular}{|c|c|c|c|c|c|c|c|c|c|c|c|c|c|c|c|c|c|}
\hline & \multicolumn{17}{|c|}{ Bogotá } \\
\hline $\mathrm{O}$ & PMx1 & 226 & 227 & 168 & 179 & 7 & 8 & $7=8$ & 8 & A & A & A & A & FSV & ISP & ISP & ISP \\
\hline $\mathrm{O}$ & PMx2 & 190 & 231 & 162 & 165 & 13 & 15 & 13 & 15 & A & $\mathrm{T}$ & A & $\mathrm{T}$ & IEX & FSP & IEX & FSP \\
\hline $\mathrm{P}$ & PMx1 & 228 & 237 & 141 & 182 & 5 & 5 & 5 & 5 & A & A & A & A & ISV & ISV & ISV & ISV \\
\hline $\mathrm{P}$ & PMx2 & 216 & 235 & 174 & 178 & 8 & 8 & 8 & 8 & A & A & A & A & ISP & ISP & ISP & ISP \\
\hline $\mathrm{P}$ & PMx3 & & 274 & 158 & 171 & & 14 & 12 & 12 & & A & A & A & & FSP & IEX & IEX \\
\hline $\mathrm{P}$ & PMx4 & & & & 193 & & & & 14 & & & & A & & & & FSP \\
\hline $\operatorname{Pr}$ & PMx1 & 229 & 247 & 176 & 183 & 3 & 5 & 4 & 4 & A & A & A & A & PSN & ISV & FSN & FSN \\
\hline $\operatorname{Pr}$ & PMx2 & 229 & 237 & 169 & 184 & 8 & 8 & 8 & 8 & A & A & A & A & ISP & ISP & ISP & ISP \\
\hline \multirow[t]{2}{*}{$\operatorname{Pr}$} & PMx3 & 211 & 330 & 157 & 231 & 11 & 14 & 11 & 14 & A & A & A & A & FSSP & FSP & FSSP & FSP \\
\hline & \multicolumn{17}{|c|}{ Tenerife } \\
\hline $\mathrm{O}$ & PMx1 & 243 & 249 & 173 & 228 & 5 & 7 & 4 & 6 & A & A & $\mathrm{T}$ & $\mathrm{T}$ & ISV & FSV & FSN & PSV \\
\hline $\mathrm{O}$ & PMx2 & 230 & 332 & 186 & 273 & 12 & 15 & 12 & 15 & A & $\mathrm{T}$ & A & $\mathrm{T}$ & IEX & FSP & IEX & FSP \\
\hline $\mathrm{P}$ & PMx1 & 229 & 242 & 177 & 234 & 4 & 7 & 8 & 4 & A & A & A & A & FSN & FSV & ISP & FSN \\
\hline $\mathrm{P}$ & PMx2 & 231 & 319 & 184 & 278 & 11 & 13 & 11 & 14 & A & $\mathrm{T}$ & A & A & FSSP & PEX & FSSP & FSP \\
\hline $\operatorname{Pr}$ & PMx1 & 244 & 276 & 194 & 227 & 4 & 6 & 4 & 2 & A & $\mathrm{T}$ & A & $\mathrm{T}$ & FSN & PSV & FSN & ISSN \\
\hline \multirow[t]{2}{*}{$\operatorname{Pr}$} & PMx2 & 242 & 302 & & 289 & 11 & 12 & & 12 & A & $\mathrm{T}$ & & $\mathrm{T}$ & FSSP & IEX & & IEX \\
\hline & \multicolumn{17}{|c|}{ Gran Canaria } \\
\hline $\mathrm{O}$ & PMx1 & 244 & 296 & 188 & 177 & 7 & 15 & 4 & 8 & A & $\mathrm{T}$ & $\mathrm{T}$ & A & FEX & FSP & FSN & ISV \\
\hline $\mathrm{O}$ & PMx2 & 231 & & 223 & 190 & 12 & & 12 & 15 & A & & A & $\mathrm{T}$ & IEX & & IEX & FSP \\
\hline $\mathrm{P}$ & PMx1 & 242 & 303 & 208 & 193 & 7 & 13 & 4 & 13 & A & $\mathrm{T}$ & A & $\mathrm{T}$ & FSV & PEX & FSN & PEX \\
\hline$P$ & PMx2 & 230 & & 227 & & 11 & & 11 & & A & & A & & FSSP & & FSSP & \\
\hline $\mathrm{Pr}$ & PMx1 & 256 & 309 & 215 & 180 & 4 & 12 & 4 & 5 & A & $\mathrm{T}$ & A & A & FSN & IEX & FSN & ISV \\
\hline $\operatorname{Pr}$ & PMx2 & 235 & & 217 & 194 & 7 & & 10 & 12 & A & & A & $\mathrm{T}$ & FSV & & PSV & IEX \\
\hline
\end{tabular}

\subsubsection{Relación pico/acento}

La Tabla 6 muestra que las oraciones con expansión en el objeto, a diferencia de las precedentes (sin expansión y con expansión en sujeto), presentan un porcentaje mayor de picos en el tonema que en el pretonema, tanto en las oraciones declarativas como en las interrogativas; se exceptúa que en las proparoxítonas de las declarativas el pretonema continúa teniendo un número mayor de picos.

En las declarativas, el pretonema tiene una estructura similar a la que se vio en las oraciones sin expansión, esto es, ningún pico se sincroniza con vocal tónica en paroxítonos y proparoxítonos puesto que se desplaza hacia la derecha alternando entre la postónica y la postpostónica. En oxítonos, aunque el pico coincide con un 
porcentaje bajo de tónicas, se imponen las átonas y a diferencia de las otras dos tipologías acentuales la pos-realización se da en la sílaba inmediatamente siguiente. En el tonema de esta misma modalidad, independientemente de la tipología acentual, el pico se desplaza una y dos sílabas a la derecha, aunque en oxítonos un porcentaje muy bajo presenta acento en la tónica coincidiendo, además, con el FSN.

Tabla 6. Alineación pico/acento léxico en función de la tipología acentual en oraciones con expansión en el objeto.

\begin{tabular}{|c|c|c|c|c|c|c|c|}
\hline & \multicolumn{6}{|c|}{ ALINEACIÓN PICO/ACENTO ORACIONES S+EXP+V+O } \\
\hline & & \multicolumn{3}{|c|}{ Declarativa } & \multicolumn{3}{|c|}{ Interrogativa } \\
\hline & & Pretonema & Tonema & Total & Pretonema & Tonema & Total \\
\hline \multirow{4}{*}{$\mathbf{O}$} & Pretónica & 0 & 0 & 0 & 0 & 0 & 0 \\
\hline & Tónica & 3,64 & 1,81 & 5,45 & 1,89 & 13,21 & 15,00 \\
\hline & Postónica & 10,91 & 9,09 & 20,00 & 5,66 & 0 & 5,66 \\
\hline & Pospostónica & 0 & 7,27 & 7,27 & 0 & 9,43 & 9,43 \\
\hline \multicolumn{2}{|c|}{ Total } & 14,55 & 18,18 & 32,73 & 7,55 & 22,64 & 30,19 \\
\hline \multirow{4}{*}{$\mathbf{P}$} & Pretónica & 0 & 0 & 0 & 0 & 0 & 0 \\
\hline & Tónica & 0 & 0 & 0 & 0 & 7,55 & 7,55 \\
\hline & Postónica & 10,91 & 10,91 & 21,82 & 7,55 & 7,55 & 15,1 \\
\hline & Pospostónica & 3,64 & 9,09 & 12,73 & 5,66 & 7,55 & 13,21 \\
\hline \multicolumn{2}{|c|}{ Total } & 14,55 & 20 & 34,55 & 13,21 & 22,65 & 35,86 \\
\hline \multirow{4}{*}{ Pr } & Pretónica & 0 & 0 & 0 & 3,77 & 0 & 3,77 \\
\hline & Tónica & 0 & 0 & 0 & 3,77 & 7,55 & 11,32 \\
\hline & Postónica & 9,09 & 3,64 & 12,73 & 3,77 & 1,89 & 5,66 \\
\hline & Pospostónica & 9,09 & 10,91 & 20 & 3,77 & 9,43 & 13,2 \\
\hline \multicolumn{2}{|c|}{ Total } & 18,18 & 14,55 & 32,73 & 15,08 & 18,87 & 33,95 \\
\hline
\end{tabular}

En el pretonema de las interrogativas un porcentaje de picos se sincroniza con la vocal tónica cuando se trata de oxítonos y proparoxítonos; sin embargo, es muy bajo en comparación con la sincronización en las átonas. El desplazamiento de los picos en los oxítonos se da en la sílaba inmediatamente siguiente a la tónica y en los paroxítonos y proparoxítonos alternan entre la postónica y la postpostónica. En el tonema de esta modalidad encontramos sincronización de pico/tónica, pero esta es superior a la sincronización de pico/átona solamente en los oxítonos; en paroxítonos y proparoxítonos la sincronización pico/átona es superior a pico/tónica. No obstante, tomando los datos en conjunto, es decir, sin diferenciar entre pretonema y tonema, existe una clara tendencia a sincronizar el pico con vocal átona con un desplazamiento hacia la derecha generando, por tanto, la posrealización del pico con independencia de la modalidad y de la tipología acentual. 


\subsubsection{Relación picos/fronteras sintagmáticas}

La Figura 9 muestra que las oraciones con expansión en el objeto presentan un comportamiento similar a las oraciones sin expansión y con expansión en el sujeto, es decir, los picos coinciden con una frontera sintagmática en la mayoría de los casos o, de forma esporádica, muy próximo a ella. En el pretonema de las oraciones declarativas, la sincronización del pico máximo con la frontera sintagmática se da en el FSN (20\%), ISV (9,09\%) y FSV (12,73\%); en el tonema el pico tonal coincide con el ISP $(16,36 \%)$ y marca la frontera sintagmática débil aunque es superior en FSSP $(18,18 \%)$ que IEX $(14,55)$.

Figura 9. Oraciones con expansión en el objeto.

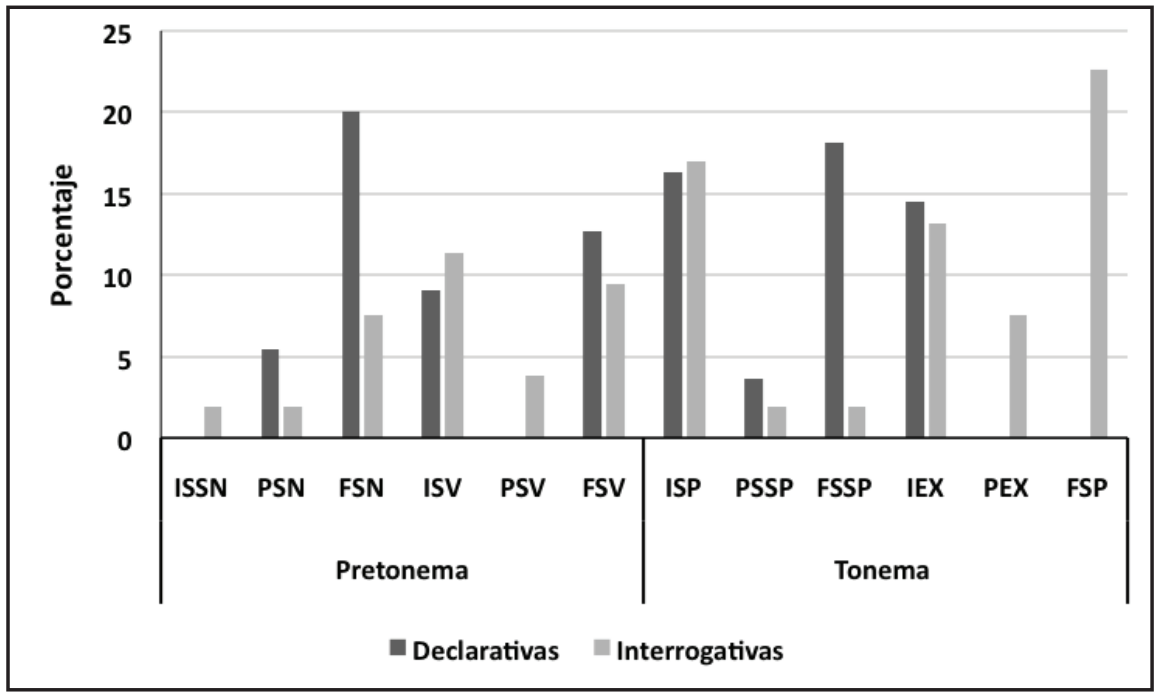

En el pretonema de las oraciones interrogativas, los picos coinciden con una frontera sintagmática: FSN (7,54\%\%), ISV (11,32\%) y FSV $(9,43 \%)$. En el tonema, por su parte, el pico tonal coincide con el ISP $(16,98 \%)$ y marca la frontera sintagmática débil, aunque es superior en el IEX (13,21\%) que en el FSSP $(1,89 \%)$. A continuación y a diferencia de las declarativas, se dan más movimientos tonales y el mayor porcentaje marca el FSP $(22,64 \%)$ que coincide con la última frontera sintagmática o, en su defecto, muy próximo al FSP (7,55\%).

Al tomar las oraciones en conjunto, podemos concluir que los picos tonales señalan invariablemente o la frontera sintagmática fuerte (SN/SV, SV/SP y FSP) o la frontera sintagmática débil.

De acuerdo con el conjunto los datos (tablas 5 y 6 y Figura 9), podemos determinar que las vocales átonas que se sincronizan con picos también lo hacen con las fronteras sintagmáticas fuerte y débil, independientemente de la tipología 
acentual. Se exceptúa un bajo porcentaje de proparoxítonas $\left(9 \%{ }^{21}\right.$ de declarativas y $3 \%{ }^{22}$ de interrogativas) que recae en la postónica del sustantivo. Además, los picos que recaen en la tónica coinciden, en su mayoría, con una frontera sintagmática o muy cerca de ella independientemente de su tipología acentual. En las oraciones declarativas esta sincronización se da solo en las oxítonas con un 5,45\%: 3,64\% en el $\mathrm{FSN}^{23}$ y $1,82 \%$ en el FSSP ${ }^{24}$.

En las oraciones interrogativas, la sincronización en los distintos acentos es la siguiente: del $15 \%$ en oxítonos ${ }^{25}$, el 13,20\% recae en FSP; el 7,5\% de las paroxítonos ${ }^{26}$ recae en PEX y, por último, del 11,32\% de los proparoxítonos ${ }^{27}$, el 9,43\% recae en el IEX.

\section{DisCUSIÓN Y CONCLUSIONES}

El presente trabajo tenía como objetivo analizar la validez de la hipótesis demarcativa en oraciones declarativas e interrogativas de voces femeninas y masculinas colombianas (Medellín y Bogotá) y canarias (Tenerife y Gran Canaria). Esta hipótesis considera que la estructura prosódica de una oración se relaciona con su estructura sintáctico-semántica; por tanto, si los picos máximos se alinean con vocales átonas y con fronteras sintagmáticas podremos sugerir que la hipótesis demarcativa se confirma en el habla canaria y colombiana.

Los resultados obtenidos muestran una tendencia general a la alineación de picos máximos con vocal átona posterior a la tónica y con frontera sintagmática. Por tanto, al igual que otros estudios (Pamies y Amorós 2005; Dorta 2006; Cuevas et al. 2007; Dorta et al. 2007), nuestra investigación corrobora la hipótesis demarcativa en el español hablado en las localidades estudiadas, al menos en el tipo de corpus formal analizado.

En relación con la sincronización entre pico máximo y acento léxico, los datos muestran que la pre-realización del pico (preshooting) ha sido insignificante y se presenta solo en el pretonema de las oraciones interrogativas proparoxítonas $(6,98 \%$ en $\mathrm{SVO} ; 1,54 \%$ en $\mathrm{S}+\mathrm{EXP}+\mathrm{V}+\mathrm{O}$ y $3,77 \%$ en $\mathrm{S}+\mathrm{V}+\mathrm{O}+\mathrm{EXP})$. Esta característica se da en todas las localidades estudiadas, excepto en Medellín. En cambio, la posrealización (overshooting) ha sido muy alta en comparación con la pre-realización y con la sincronización entre pico y tónica.

En lo que respecta a la pos-realización, en las declarativas se observa una tendencia mayor a la sincronización de los picos con postónica que con pos-postónica

\footnotetext{
${ }^{21} \quad$ En mujer de Medellín y Bogotá y en el hombre de Medellín y Gran Canaria.

22 En el hombre de Medellín.

23 En las declarativas oxítonas del hombre de Tenerife y Gran Canaria.

24 En las declarativas oxítonas de la mujer de Medellín.

25 No se da en el hombre de Medellín.

26 No se da en el hombre y la mujer de Gran Canaria y en la mujer de Medellín y Tenerife.

27 Solo en los informantes canarios.
} 
$(54,05 \%$ y $43,25 \%$ en SVO; $52,39 \%$ y $47,61 \%$ en $\mathrm{S}+\operatorname{ExpVO} ; 54,55 \%$ y $40 \%$ en $\mathrm{SVO}+$ Exp, respectivamente). En las interrogativas, en cambio, esta tendencia se da en las oraciones más breves SVO (37,21\% y 16,30\%); en cambio, se invierte en las interrogativas S+ExpVO (29,23\% y 41,54\%) y SVO+Exp $(26,42 \%$ y $35,84 \%)$. No obstante, al tomar los datos en conjunto la sincronización de pico con postónica presenta un mayor porcentaje.

En cuanto a la sincronización entre pico/vocal átona, se concluye que en las declarativas SVO es del 97,30\% (pretonema 72,98\%; tonema 24,32\%), en S+ExpVO es del $100 \%$ (pretonema $80,96 \%$; tonema 19,04\%) y en SVO+Exp es de $94,54 \%$ (pretonema 43,63\%; tonema 50,91\%). En las interrogativas la sincronización con átona desciende: en SVO al 60,46\% (pretonema 41,86\%; tonema 18,60\%); en S+ExpVO al 72,30 (pretonema 53,84\%; tonema 18,46\%) y en SVO+Exp al 66,03\% (pretonema 30,19\%; tonema 35,84\%). Por otra parte, independientemente de la estructura sintáctica o de la tipología acentual, existe una sincronización entre pico/ átona/frontera sintagmática o muy próxima a esta última.

Al considerar la sincronización de los picos con vocal tónica se ha observado que en las oraciones declarativas SVO es solo del 2,7\% y se ubica en el pretonema; en $\mathrm{S}+\mathrm{ExpVO}$ no hay casos de sincronización y SVO+Exp el porcentaje es un $5,45 \%$ (pretonema 1,8\%; tonema 3,6\%). En las oraciones interrogativas, en cambio, la sincronización se produce en un $39,53 \%$ en SVO (pretonema 9,3\%; tonema $30,23 \%$ ), en un $27,69 \%$ en $\mathrm{S}+\operatorname{ExpVO}$ (pretonema $1,5 \%$; tonema $26,19 \%$ ) y en un $33,96 \%$ SVO+Exp (pretonema 5,66\%; tonema 28,30\%). De este modo, aunque en términos generales la sincronización de picos con vocal tónica es baja, la modalidad declarativa muestra un porcentaje inferior a la interrogativa y, a su vez, el tonema de esta modalidad presenta un mayor porcentaje que el pretonema en las tres estructuras sintácticas. Al tomar el $100 \%$ de las vocales tónicas que se sincronizan con picos en el tonema de las oraciones interrogativas, observamos que el mayor porcentaje corresponde a las oxítonas $(43,47 \%)$, frente a las paroxítonas y proparoxítonas (igualadas en un 28,26\%). Indiscutiblemente, la tónica de las oxítonas coincide con una frontera sintagmática y, por tal motivo, la sincronización se presenta por una relación entre pico y frontera y no entre pico y acento como lo hemos mencionado en el análisis detallado de los tres tipos de oración analizados.

En términos generales, las cuatro localidades estudiadas sincronizan los picos tonales con vocales átonas y también con una frontera sintagmática. En el total de la sincronización entre pico con vocal tónica los informantes canarios tienden a presentar un mayor porcentaje $(71,92 \%)$ que los colombianos $(28,07 \%)$, sobre todo los de Gran Canaria (38,59\%) cuyo porcentaje es el más alto, mientras que el de Bogotá $(8,7 \%)$ es el más bajo.

Al observar específicamente el tonema de las oraciones interrogativas, en Colombia el mayor porcentaje de sincronización está relacionado con las oxítonas (25\%), seguido de las paroxítonas $8,33 \% \mathrm{y}$, finalmente, de las proparoxítonas 5,55\%; en Canarias la distribución de los casos en las tres tipologías acentuales se produce equitativamente, siendo un $30,55 \%$ para las oxítonas, y también para las proparoxítonas y un $27,77 \%$ para las paroxítonas.

En cuanto al sexo, el comportamiento de hombres y mujeres tiende a ser similar en relación con la sincronización entre pico/vocal átona. Sin embargo, en la sincronización pico/vocal tónica hay algunas diferencias: tomando el 100\% de 
las vocales tónicas observamos que las mujeres colombianas, en comparación con los hombres, producen el mayor porcentaje de sincronización $(26,31 \%, 1,75 \%$, respectivamente); en cambio, los hombres y mujeres de canarias presentan una distribución similar.

Tomando todos los datos en conjunto, esto es oraciones SVO, S+ExpVO y SVO+Exp, hemos comprobado que la sincronización pico/átona corresponde al 80,68\% de los casos, de los cuales se da sincronización con frontera sintagmática en un 71,86\% y el resto con una frontera próxima. Atendiendo a la tipología acentual observamos que las paroxítonas son las que presentan un porcentaje mayor de casos $(30,85 \%)$ y en su totalidad se sincronizan con frontera sintagmática; siguen las proparoxítonas con un $29,83 \%$ dándose la sincronización en un $22,72 \%$ de casos; finalmente, en las oxítonas registramos un $20 \%$ de casos con una sincronización del 18,30\%.

La sincronización entre pico y tónica corresponde solo al 19,32\%. Las oxítonas son las que presentan un mayor porcentaje de casos $(8,81 \%)$ de los que la sincronización con frontera sintagmática es de un 7,78\%; las paroxítonas registraron un 5,08\% y no presentan sincronización con frontera sintagmática y, por último, a las proparoxítonas les corresponde un $5,43 \%$ de casos de los cuales un 5,08\% se sincronizan con una frontera.

\section{Conclusión general}

Los datos del presente estudio muestran que en habla formal del español, independientemente de la localidad, el género o la modalidad, la tendencia general es la pos-realización del pico y su sincronización con frontera sintagmática. La mayor diferencia entre modalidades radica en que el tonema de las interrogativas propicia más la sincronización de los picos con vocales tónicas. Esta sincronización es más frecuente en canarias que en Colombia y, además, su distribución en función de la tipología acentual es sistemática en los hablantes canarios, mientras que en los colombianos hay un mayor porcentaje en las oxítonas. Por último, tanto en el presente trabajo como en otros que le preceden, se analiza un corpus formal de oraciones por lo que habría que ver si en otros más espontáneos se verifica la relación entre picos tonales y fronteras sintagmáticas.

\section{OBRAS CITADAS}

Contini, Michell. 2005. "2e Séminaire international du projet AMPER", Projet AMPER, Géolinguistique-Hors série n.3, Grenoble, Centre de Dialectologie, Université Stendhal Grenoble 3: I-XI.

Cuevas Alonso, Miguel et al. 2007. "Entonación, acento y límites sintagmáticos en sujetos con y sin expansión en asturiano central”. Eds. González González, Manuel, Elisa Fernández Rei y Begoña González Rei. Actas del III Congreso de Fonética Experimental. Santiago de Compostela: Ed. Xunta de Galicia. 223-233.

Díaz, Chaxiraxi et al. 2016 (en prensa). "Intonation across Two Border Areas in the North Andean Region. Mérida Venezuela and Medellin Colombia”. Spanish in Context. John Benjamins.

Dorta, Josefa. 2006. "Función delimitadora: entonación y acento en un corpus de habla ex- 
perimental". Actes del VII Congrés de Lingüistica General. Barcelona: Universitat de Barcelona. Ed. en CDrom, ISBN 84-475-2086-8, Secció Gramàtica. Forma i signe.

Dorta, Josefa et al. 2007. "Función demarcativa de la entonación”. Revista de Filología de la Universidad de La Laguna 25: 143-153.

Face, Timothy. 2002. "Spanish evidence for pitch-accent structure". Linguistics 40.2: 319-345.

Fernández Planas, Ana María. 2005. "Datos generales del proyecto AMPER en España”. Estudios de Fonética Experimental XIV: 327-353.

Garrido Almiñana, Juan María et al. 1993. "Prosodic differences in reading style. Isolated vs. Contextualized Sentences". Eurospeech'93. 3rd European Conference on Speech Communication and Technology. Berlin, Germany, 21-23 September. Vol I. 573-576.

Ham Rosales, Lorena. 2003. Entonación. Índice de identidad dialectal. Documentos CESO. Bogotá: publicaciones de la Universidad de los Andes. 48.

López Bobo, María Jesús et al. 2007. “Análisis y representación de la entonación. Replanteamiento metodológico en el marco del proyecto AMPER". La prosodia en el ámbito lingüístico Románico. Ed. Josefa Dorta. Madrid-Santa Cruz de Tenerife: La Página ediciones S/L, Colección Universidad. 17-34.

Llisterri, Joaquim et al. 1995. "Factors affecting F0 peak displacement in Spanish". Eurospeech'95 Proceedings. ESCA 4th European Conference on Speech Communication and Technology. Eds. José Manuel Pardo, Emilia Enríquez, Javier Ortega, Javier Ferreiros, Javier Macías y Francisco José Valverde. Madrid, 18-21 Septiembre, Vol. 3: 2061-2064.

Martínez Celdrán, Eugenio y Ana Fernández Planas. 2006. "Hacia una geoprosodia de las lenguas íbero-romances en la "Web". Letras de Hoje 41: 9-22.

Muñetón, Mercedes. 2016 (en prensa). "La F0, duración e intensidad de las oraciones interrogativas absolutas en un informante varón de Medellín". Estudios de Fonética Experimental 25:167-192.

Muñetón, Mercedes y Dorta Josefa. 2015. "La entonación declarativa e interrogativa en el español colombiano de Medellín. Voz femenina vs. Masculina". Boletín de Filología 50.2: 103-122.

Martin, Philippe. 1987. "Prosodia and Rythmic Structures in French", Linguistics, 25/5, pp. 925-949.

1997. "L'intonation. Analyse instrumentale et modèles". Lablita, Collezioni dei Preprint, 4, Laboratorio Linguistico del Dipartimento di Italianistica: Università di Firenze.

Osorio, Gloria y Diana Muñoz. 2011. "La entonación del enunciado interrogativo en el español de la ciudad de Medellín”. Lingüística y Literatura 32.60: 209-226.

Prieto, Pilar et al. 1995. "Tonal Alignment Patterns in Spanish". Journal of Phonetics 23: 429-451.

Pamies Bertrán, Antonio, et al. 2002. "Umbrales tonales en el español peninsular”. Actas del II Congreso de Fonética Experimental. Sevilla: Universidad de Sevilla. 272-278.

Pamies Bertrán, Antonio y Mari Cruz Amorós Céspedes. 2005. "Pico tonal, acento y fronteras morfo-semánticas. Experimento con hablantes granadinos". Estudios de Fonética Experimental XIV: 201-223.

Pamies Bertrán, Antonio, et al. 2007. "Esquemas entonativos declarativos del habla de Almería”. La prosodia en el ámbito lingüístico Románico. Ed. Josefa Dorta. Madrid-Santa Cruz de Tenerife: La Página ediciones S/L, Colección Universidad. 299-311.

Rietveld, C. M. y Carlos Gussenhoven. 1985. "On the relation between pitch excursion size and prominence". Journal of Phonetics 13: 299-308.

Sosa, Juan Manuel. 1995. "Nuclear and pre-nuclear tonal inventories and the phonology of Spanish declarative intonation". Proceedings of the 13th ICPhS. Eds. K. Elenius y R. Branderand, Estocolmo. Vol. 4: 646-649.

Sosa, Juan Manuel 1999. La Entonación del español. Su estructura fónica, variabilidad y dialectología. Madrid: Cátedra. 
